\title{
Nizamis Schatzkammer der Geheimnisse. Eine Untersuchung zu Mahzan ul-asrar. Wiesbaden, Reichert Verlage, 2005, 419 p.
}

\section{Christine Van Ruymbeke}

\section{(2) OpenEdition}

1 Journals

Édition électronique

URL : http://journals.openedition.org/abstractairanica/21261

DOI : 10.4000/abstractairanica.21261

ISSN : 1961-960X

Éditeur :

CNRS (UMR 7528 Mondes iraniens et indiens), Éditions de l'IFRI

\section{Édition imprimée}

Date de publication : 15 mai 2007

ISSN : 0240-8910

Référence électronique

Christine Van Ruymbeke, « Nizamis Schatzkammer der Geheimnisse. Eine Untersuchung zu Mahzan ul-asrar. Wiesbaden, Reichert Verlage, 2005, 419 p. », Abstracta Iranica [En ligne], Volume 28 | 2007, document 358, mis en ligne le 18 septembre 2007, consulté le 25 septembre 2020. URL : http:// journals.openedition.org/abstractairanica/21261; DOI : https://doi.org/10.4000/abstractairanica. 21261

Ce document a été généré automatiquement le 25 septembre 2020.

Tous droits réservés 


\title{
Nizamis Schatzkammer der Geheimnisse. Eine Untersuchung zu Mahzan ul-asrar. Wiesbaden, Reichert Verlage, 2005, 419 p.
}

\author{
Christine Van Ruymbeke
}

1 Voici enfin un ouvrage nous présentant, de manière complète, solide et fouillée, le premier mațnavī de Niẓāmī de Ganja: le MaHzan ul-asrār, ou Magasin des Secrets est généralement présenté comme une œuvre difficile et mystérieuse, (Dieses ungemein dichte Werk erschliesst sich dem Verstandnis nicht leicht, p. v) au contenu didacticophilosophique, et au très riche réseau d'emplois métaphoriques. L'œuvre fut composée par Nizāāī en l'année 1156-57 (ou en 1174). Elle est écrite en mètre sarī mațwī mawqūf et contient plus de 2.200 vers. Pour son étude, $R$. Wuersch emploie l'édition critique de ‘A. 'Alīzāde (1960), complétée par celle de V. Dastgirdī (1334).

2 L'ouvrage de Wuersch est constitué d'une introduction, de six chapitres, suivis d'une conclusion, d'une liste d'abréviations, d'une bibliographie, et de trois indexes (citations coraniques, noms propres, mots employés). Au cours des chapitres, Wuersch nous donne aussi de nombreuses traductions en allemand de vers souvent difficiles, qu'elle accompagne d'un commentaire éclairant.

3 Le premier chapitre (Werkgeschichte- pp. 1-30) contient « l'Histoire de l'œuvre » et passe donc en revue ce que l'on sait sur l'A., sur ce premier matnavī (tant l'œuvre elle-même, que ses commentaires, éditions, traductions et études) sur son commanditaire, sur la relation déjà bien établie entre le mațnavī de Sanā’ì (Hadīqat ul-haqīqa) et le MaHzan et sur la réception de l'œuvre dans les milieux persans, turcs et indiens, mais également en Europe. Le deuxième chapitre (Aufbau und formale Gliederung, pp. 31-71) nous présente la découpe du matnavī en un prologue (qui représente un tiers du matnavī), suivis de 20 chapitres et d'un bref épilogue. Chacun des 20 chapitres consiste en une histoire dont la morale n'a pas énormément d'impact sur le développement du thème d'intérêt didactique qui suit. Des thèmes soufis, tel celui de la préséance de l'âme sur le 
corps, sont présents, mais Wuersch considère qu'ils sont subordonnés aux thèmes religieux, éthiques et didactiques (p. 35) L'intérêt du poète va au conseil à l'homme, non au mystique. Les conseils de morale au souverain resurgissent comme des fils rouges au cours des chapitres : dans cette première œuvre déjà, Nizāaīi se rapproche de l'optique de « miroir de prince », qui restera au centre de ses œuvres suivantes. Les troisième et quatrième chapitres (Sprache und Stil, pp.72-126 et Textstruktur, pp.127-171) nous introduisent au cœur de l'étude de Wuersch. Il s'agit d'appréhender tant le style poétique, l'art et la technique poétique de Nizāāī, déjà complets dans cette première œuvre ("Sie zu beschreiben und zu analysieren ist fur eine umfassende Wurdigung von Nizamis Kunst unabdingbar", p. vi), que la structure des parties homélitiques et narratives du texte. Le cinquième chapitre (Werkbestimmende Themen, pp. 172-270) étudie les thèmes principaux du MaHzan. Enfin, le sixième chapitre (Die zwanzig Erzahlungen, pp. 271-363) termine l'étude de Wuersch par une traduction et une analyse des sources et motifs des 20 paraboles.

4 Le seul regret que l'on puisse exprimer est le fait que soit rédigé en allemand un ouvrage indispensable dans la bibliothèque des spécialistes de Nizāaī tout comme dans celle de toute personne s'intéressant à la littérature médiévale persane, ce qui rendra sa lecture et sa consultation peut-être moins répandues qu'il ne le mérite parmi le public francophone et anglophone.

INDEX

Thèmes : 11.1.1. Littérature persane classique

\section{AUTEURS}

CHRISTINE VAN RUYMBEKE

Cambridge 